This item was submitted to Loughborough's Research Repository by the author.

Items in Figshare are protected by copyright, with all rights reserved, unless otherwise indicated.

\title{
Innovative analysis and use of high-resolution DTMs for quantitative interrogation of Earth-surface processes
}

PLEASE CITE THE PUBLISHED VERSION

http://dx.doi.org/10.1002/esp.3616

\section{PUBLISHER}

(c) John Wiley \& Sons, Ltd.

\section{VERSION}

AM (Accepted Manuscript)

\section{PUBLISHER STATEMENT}

This work is made available according to the conditions of the Creative Commons Attribution-NonCommercialNoDerivatives 4.0 International (CC BY-NC-ND 4.0) licence. Full details of this licence are available at: https://creativecommons.org/licenses/by-nc-nd/4.0/

\section{LICENCE}

CC BY-NC-ND 4.0

\section{REPOSITORY RECORD}

Passalacqua, Paola, John K. Hillier, and Paola Tarolli. 2019. "Innovative Analysis and Use of High-resolution Dtms for Quantitative Interrogation of Earth-surface Processes”. figshare. https://hdl.handle.net/2134/16437. 


\title{
Innovative analysis and use of high-resolution DTMs for quantitative interrogation of Earth-surface processes
}

\author{
Paola Passalacqua ${ }^{1}$, John Hillier $^{2}$, Paolo Tarolli ${ }^{3}$
}

${ }^{1}$ Department of Civil, Architectural, and Environmental Engineering and Center for Research in Water Resources, The University of Texas at Austin, 301 E. Dean Keeton St. STOP C1700, Austin, TX, 78712-2100, USA.

${ }^{2}$ Department of Geography, Loughborough University, Leicestershire, LE11 3TU, UK.

${ }^{3}$ Department of Land, Environment, Agriculture and Forestry, University of Padova, Viale dell'Università 16, Legnaro (PD) 35020, ITALY.

\begin{abstract}
This is the era of digital landscapes; the widespread availability of powerful sensing technologies has revolutionized the way it is possible to interrogate landscapes in order to understand the processes sculpting them. Vastly greater areas have now been acquired at 'high resolution': currently $10 \mathrm{~s}$ of m globally to millimetric precision and accuracy locally. This permits geomorphic features to be visualized and analysed across the scales at which Earth-surface processes operate. Especially exciting is the capturing of process dynamics in repeated surveying, which will only become more important with low-cost accessible data generation through techniques such as Structure from Motion (SfM). But the key challenge remains; to interpret high resolution Digital Terrain Models (DTMs), particularly by extracting geomorphic features in robust
\end{abstract}


and objective ways and then linking the observed features to the underlying physical processes. In response to the new data and challenges, recent years have seen improved processing of raw data into DTMs, development of data fusion techniques, novel quantitative analysis of topographic data, and innovative geomorphological mapping. The twelve papers collected in this volume sample this progress in interrogating Earth-surface processes through the analysis of DTMs. They cover a wide range of disciplines and spatio-temporal scales, from landslide prone landscapes, to agriculturally modified regions, to mountainous landscapes, and coastal zones. They all, however, showcase the quantitative exploitation of information contained in highresolution topographic data that we believe will underpin the improvement of our understanding of many elements of Earth-surface processes. Most of the papers introduced here were first presented in a conference session at the European Geosciences Union General Assembly in 2011.

\section{Introduction}

With the availability of high resolution DTMs previously inconceivable advances in the analysis of the Earth's land surface, sea floor, and planetary terrains have been possible. Lidar derived data, for example, are now used in a variety of disciplines, from geomorphology, to hydrology, to tectonics and geoarchaeology [Glennie et al., 2013; Tarolli, 2014]. Recent research advances have included techniques to objectively and robustly explore high resolution DTMs, which feed into modelling and analysis to further our understanding of landscape forming processes. For example, methods have been proposed for the semi-automatic and automatic extraction of channels and channel 
heads [Lashermes et al., 2007; Passalacqua et al., 2010a,b; Sofia et al., 2011; Cazorzi et al, 2013; Pelletier, 2013], channel morphology [Passalacqua et al., 2012; Fisher et al., 2013], and fluvial terraces [Stout and Belmont, 2013]; the identification of landslide prone areas [Booth et al., 2009; Tarolli et al., 2012]; the characterization of landslide morphology [McKean and Roering, 2004; Glenn et al., 2006; Ardizzone et al., 2007], glacial landforms [e.g., Smith et al., 2009; Hillier and Smith, 2012], submarine volcanoes [e.g., Behn, 2004; Hillier, 2008], and depositional features of alluvial fans [Staley et al, 2006; Frankel and Dolan, 2007; Cavalli and Marchi, 2007]. In terrestrial subaerial geomorphology lidar is the remote sensing technique that has most recently contributed the most. Other techniques such as SAR (Synthetic Aperture Radar) offer opportunities to further investigate Earth surface processes such as landsliding [e.g. Roering et al., 2009; Bovenga et al., 2012; Berti et al., 2013; Raucoules et al., 2013; Zhao et al., 2013] and to analyse river bed morphology [Marcus and Fonstad, 2010].

We are now observing an abrupt increase of available higher resolution data and challenges in feature extraction and interpretation of geomorphic features remain. In order to collect recent research advancements and motivate further research in this direction, we organized a 'Digital Landscapes' session at the European Geosciences Union General Assembly in 2011, and it has continued successfully every year since then. The session was focused on objective, robust, reproducible, and quantitative methods of analysis of DTMs to extract geomorphic features from high-resolution topographic data and to bridge the gap between geomorphic form and its formational processes. We solicited presentations about methodological developments that create exciting new observations and unlock the potential wealth of new insights into 
geomorphic processes recorded in DTMs. This special issue collects twelve such papers that span a variety of spatio-temporal scales and disciplines. A brief summary of the papers that are part of this special issue is given below.

\section{Applications}

Feature recognition and quantification

Barneveld et al. [2013] analyse the suitability of Terrestrial Laser Scanners (TLS) for the accurate measurement of soil micro-topography. Tests performed on three agricultural fields show that the choice of resolution and viewpoints plays a critical role in the accuracy of the results. Precision and accuracy of the DEMs rapidly decline with decreasing resolution due to the presence of sub-grid roughness elements at the soil surface. Viewpoints should be chosen such that areas of interest are properly covered when multi-temporal analysis of soil properties is performed in order to assess soil roughness dynamics or erosion/deposition patterns.

Corsini et al. [2013] focus on techniques to map and monitor a slow moving compound rockslide in the northern Apennines in Italy. ALS, multi-temporal TLS, and Automated Total Station (ATS) measurements are integrated using an Iterative Closest Point procedure. They obtain a better DTM than would be possible from any data set taken separately. The landslide features are mapped on the resulting high resolution DTM. Movements of the landslide elements up to $20 \mathrm{~cm}$ are estimated with sequential TLS surveys. Differences are estimated using a surface matching approach, detecting changes down to $\sim 3 \mathrm{~cm}$. This analysis confirms the applicability of laser scanning to 
quantify slope instability processes, and highlights the advantages of blending measurement approaches.

D'Agostino and Bertoldi [2014] propose a method to calculate the Management Priority Index (MPI) to rank sediment sources within a catchment based on their potential to deliver debris-flow volumes to a point of interest. Three sub-indicators are proposed to define priority of intervention: (i) a susceptibility indicator that quantifies the overall potential to generate debris flows; (ii) a triggering indicator; and (iii) a volume budget indicator to estimate the deliverable volume to a selected outlet. The method is tested with surveys and field observations on an alpine catchment, the Rio Gadria in Italy, characterized by several active shallow landslides and bare soil zones.

Hillier and Smith [2014] test multiple semi-automated techniques to quantify drumlin height, $H$, and volume, $V$, using synthetic DEMs [Hillier and Smith, 2012] as a diagnostic tool. From this analysis, guidelines on how best to quantify glacial bedforms' 3D attributes are proposed. Specifically, three analysis steps are suggested to avoid systematic biases and sensitivity to outliers: (i) declutter the DEM for estimating $H$ but not $V$; (ii) remove the height data within the drumlin; and (iii) use Delaunay triangulation to interpolate across the hole and estimate the basal surface. The analysis is validated in western Central Scotland, but is argued to be generally applicable.

Schwanghart et al. [2013] test a state-of-the-art carving algorithm for flow network derivation in a low-relief agricultural landscape characterized by a large number of spurious topographic depressions. Their results show that the investigated algorithm fails to reconstruct a benchmark network in terms of carving energy, distance, and a topological network measure. The authors propose modifications to the algorithm to 
enhance local variations and incorporate possible channel locations. Siart et al. [2013] propose a multi-method approach based on a fusion of TLS and subsurface geophysical data, namely seismic and electrical tomography, to investigate karst depressions and quantify their geomorphometric characteristics. Dolines in the Dikti Mountains of East Crete are used as a case study. The subsurface data provide better volume estimates than the TLS DTMs alone by accounting for infill, and also reduce ambiguities in the mode of origin of the features. Thus, better characterization of dolines in terms of their geometry and dominant geomorphologic processes acting during their formation appears possible through data integration. The impact of different DEMs and the influence of data resolution are analysed and guidelines for data fusion proposed.

Székely et al. [2014] adapt an algorithm originally developed for building identification in $3 \mathrm{D}$ cityscapes, turning it to the recognition of ignimbrite sheets in a region of the Central Andes from an SRTM Digital Elevation Model (DEM). The method consists of robustly fitting quasi-planar surfaces to the data and segmenting the surface in order to distinguish volcanic sheets from less planar features such as gullies and tectonic faults. The maps obtained are argued to be usefully different from other methods.

Tseng et al. [2013] analyse lidar-derived DTMs acquired in 2005 and 2010 to obtain landslide-induced sediment volumes resulting from a single catastrophic typhoon event in a heavily forested mountainous area of Taiwan. Each landslide volume is calculated by subtraction of the 2005 DTM from the 2010 DTM and a volume-area relationship is obtained and validated in 11 small to medium-sized catchments. The results suggest good agreement between the calculation from DTMs and the regression formula. 
Interrogation of Earth-surface processes

de Michieli Vitturi and Arrowsmith [2013] analyse the temporal evolution of simple landforms such as cinder cones by nonlinear diffusive processes through the use of a new 2D numerical model. The model employs well-established and accurate numerical mathematics and high-resolution DEMs. A spatially and temporally variable sediment transport rate scaled nonlinearly by the ratio of local slope to critical slope is employed to account for landscape heterogeneity. The results suggest that: (i) the maximum diffusion at the critical slope controls final morphology, especially approaching steady state; (ii) 2D solution of the model accounts for sediment flux convergence or divergence in the profile; (iii) the boundary behaviour of a given landscape element affects the behaviour within the domain.Mitchell et al. [2013] examine high-resolution multibeam sonar data from three areas with extreme tidal currents to understand whether Holocene tidal currents are effective at eroding bedrock: Minas Passage (Bay of Fundy), Strait of Messina (Italy), and Bristol Channel (UK). Little evidence is found in the data. Shear stresses, $\tau$, of extreme tidal streams in the UK are compiled and compared to $\tau$ in mountainous rivers where long-term rates of erosion are comparable to tectonic uplift rates, and are thus geomorphologically significant. The results suggest that tidal shear stresses, which are largely less than $10^{1} \mathrm{~Pa}$, are too small to erode bedrock by quarrying or plucking mechanisms, which usually require $>10^{2} \mathrm{~Pa}$ in rivers. Greater stresses, associated with enhanced tidal ranges during glacial low-stands, particularly in the Atlantic Ocean, may have led to sufficiently strong currents for bedrock abrasion to occur locally. 
Sailer et al. [2014] analyse the effect of DTM differencing error on the quantification of geomorphic processes. DTM differencing at several grid resolutions (from $0.25 \mathrm{~m}$ to 10 m) derived from ALS data is compared to accurate differencing calculated using point cloud data. Errors in differencing are related to landscape topographic attributes such as slope and surface roughness. It is found that errors increase with lower point density, higher values of slope, and surface roughness. The higher the error, the greater the differences between two elevation datasets have to be in order to quantify certain morphodynamic processes.

Sofia et al. [2013] analyse minimum curvature distributions to identify the statistical signature of two types of lidar DTM errors (outliers and striping artifacts) in the derived estimates. The analysis shows the importance of modelling these errors correctly to obtain reliable curvature estimates. For DTMs without errors, the scale-dependent change in curvature distribution is primarily controlled by real morphology, while when DTMs include errors, curvature distributions are controlled by outliers and striping artifacts. Error propagation depends on its distribution, spatial correlation, and scale of analysis.

\section{Concluding remarks and future opportunities}

The availability of high resolution DTMs offers great opportunities for the investigation of Earth-surface processes. New techniques have been proposed to robustly and objectively extract geomorphic features from high-resolution data and to use such information to further our understanding of Earth-surface processes. The future perhaps is even more of an exciting prospect. Specifically, although we are not the first to note 
these trends, we envisage great interest in the following approaches: (a) increased use of multi-temporal DTMs as planning and actuating carefully targeted repeated surveys becomes tractable for more researchers. Capturing dynamic changes gives direct insight into landscape evolution and enables further testing of modelling approaches. (b) More applications of SfM (Structure from Motion) techniques including the use of unmanned aerial vehicles (UAVs), that with respect to other remote sensing technologies (e.g. airborne or terrestrial laser scanner) offer low cost surveying, while

preserving suitable accuracy and resolution; (c) further development of techniques for the direct exploitation of point cloud data which preserve more terrain information than DTMs. Of course, all these approaches will require the development of innovative and quantitative analysis techniques as the ones presented in this issue in order for observations to provide insight into the processes shaping our Planet.

\section{Acknowledgments}

We would like to thank all those who reviewed the papers in this Special Issue. We are also grateful to the Managing Editor Stuart Lane, and the Assistant Editor Fiona Kirkby for both their support and help. 


\section{References}

Ardizzone F, Cardinali M, Galli M, Guzzetti F, Reichenbach P. 2007. Identification and mapping of recent rainfall-induced landslides using elevation data collected by airborne LiDAR. Natural Hazards and Earth System Sciences 7: 637-650.

Barneveld RJ, Seeger M, Maalen-Johansen I. 2013. Assessment of terrestrial laser scanning technology for obtaining high-resolution DEMs of soils. Earth Surface Processes and Landforms 38: 90-94.

Behn MD, Sinton JM, Deitrick RS. 2004. Effect of the Galapagos hotspot on seamount volcanism along the Galapagos Spreading Center. Earth and Planetary Science Letters 217: $331-347$.

Berti M, Corsini A, Franceschini S, lannacone JP. 2013. Automated classification of Persistent Scatterers Interferometry time series. Natural Hazards and Earth System Sciences 13: 1945-1958.

Booth AM, Roering JJ, Perron JT. 2009. Automated landslide mapping using spectral analysis and high-resolution topographic data: Puget Sound lowlands, Washington, and Portland Hills, Oregon. Geomorphology 109: 132-147.

Bovenga F, Wasowski J, Nitti DO, Nutricato R, Chiaradia MT. 2012. Using COSMO/SkyMed X-band and ENVISAT C-band SAR interferometry for landslides analysis. Remote Sensing of Environment 119: 272-285.

Cazorzi F, Dalla Fontana G, De Luca A, Sofia G, Tarolli P. 2013. Drainage network detection and assessment of network storage capacity in agrarian landscape. Hydrological Processes 27: 541-553. 
Cavalli M, Marchi L. 2007. Characterization of the surface morphology of an alpine alluvial fan using airborne LiDAR. Natural Hazards and Earth System Sciences 8: 323333.

Corsini A, Castagnetti C, Bertacchini E, Rivola R, Ronchetti F, Capra A. 2013. Integrating airborne and multi-temporal long-range terrestrial laser scanning with total station measurements for mapping and monitoring a compound slow moving rock slide. Earth Surface Processes and Landforms 30: 1330-1338.

D'Agostino V, Bertoldi G. 2014. On the assessment of the management priority of sediment source areas in a debris-flow catchment. Earth Surface Processes and Landforms DOI: 10.1002/esp.3518.

de Michieli Vitturi M, Arrowsmith R. 2013. Two-dimensional nonlinear diffusive numerical simulation of geomorphic modifications to cinder cones. Earth Surf. Process. Landforms. 38: 1432-1443, DOI: 10.1002/esp.3423.

Frankel KL, Dolan JF. 2007. Characterizing arid region alluvial fan surface roughness with airborne laser swath mapping digital topographic data. Journal of Geophysical Research 112: F02025, DOI:10.1029/2006JF000644.

Glenn NF, Streutker DR, Chadwick DJ, Tahckray GD, Dorsch SJ. 2006. Analysis of LiDAR-derived topography information for characterizing and differentiating landslide morphology and activity. Geomorphology 73: 131-148.

Glennie CL, Carter WE, Shresta RL, Dietrich WE. 2013. Geodetic imaging with airborne LiDAR: the Earth's surface revealed. Reports on Progress in Physics 76: 086801, DOI: 10.1088/0034-4885/76/8/086801. 
Gran KB, Belmont P, Day SS, Finnegan N, Jennings CE, Lauer JW, Wilcock PR. 2011. Landscape evolution in south-central Minnesota and the role of geomorphic history on modern erosional processes. GSA Today 21: 7-9.

Hillier JK. 2008. Seamount (submarine volcano) detection and isolation with a modified wavelet transform. Basin Research 20: 555-573.

Hillier JK, Smith M. 2012. Testing 3D landform quantification methods with synthetic drumlins in a real DEM. Geomorphology 153: 61-73, DOI:10.1016/j.geomorph.2012.02.009

Hillier J, Smith MJ. 2014. Testing techniques to quantify drumlin height and volume; synthetic DEMs as a diagnostic tool. Earth Surface Processes and Landforms. DOI: 10.1002/esp.3530.

Lashermes B, Foufoula-Georgiou E, Dietrich WE. 2007. Channel network extraction from high resolution topography using wavelets. Geophysical Research Letters 34: L23S04, DOI:10.1029/2007GL031140.

Marcus WA, Fonstad MA. 2010. Remote sensing of rivers: the emergence of a subdiscipline in the river sciences. Earth Surface Processes Landforms 35: 1867-1872. McKean J, Roering JJ. 2004. Objective landslide detection and surface morphology mapping using high-resolution airborne laser altimetry. Geomorpholology 57: 331-351, DOI:10.1016/S0169-555(03)00164-8.

Mitchell NC, Huthnance JM, Schmitt T, Todd B. 2013. Threshold of erosion of submarine bedrock landscapes by tidal currents. Earth Surface Processes Landforms 38: 627-639, DOI: 10.1002/esp.3347 
Passalacqua P, Trung TD, Foufoula-Georgiou E, Sapiro G, Dietrich WE. 2010a. A geometric framework for channel network extraction from lidar: Nonlinear diffusion and geodesic paths. Journal of Geophysical Research 115: F01002, DOI:10.1029/2009JF001254.

Passalacqua P, Tarolli P, Foufoula-Georgiou E. 2010b. Testing space-scale methodologies for automatic geomorphic feature extraction from lidar in a complex mountainous landscape. Water Resources Research 46: W11535, DOI: 10.1029/2009WR008812

Passalacqua P, Belmont P, Foufoula-Georgiou E. 2012. Automatic geomorphic feature extraction from lidar in flat and engineered landscapes. Water Resources Research 48: W03528. DOI:10.1029/2011WR010958.

Raucoules D, De Michele M, Malet JP, Ulrich P. 2013. Time-variable 3D ground displacements from high-resolution synthetic aperture radar (SAR). Application to La Valette landslide (South French Alps). Remote Sensing of Environment 139: 198-204. Roering JJ, Stimely LL, Mackey BH, Schmidt DA. 2009. Using DInSAR, airborne LiDAR, and archival air photos to quantify landsliding and sediment transport. Geophysical Research Letters 36: L19402, DOI.10.1029/2009GL040374.

Sailer R, Rutzinger M, Rieg L, Wichmann V. 2014. Digital elevation models derived from airborne laser scanning point clouds: appropriate spatial resolutions for multi-temporal characterization and quantification of geomorphological processes. Earth Surface Processes and Landforms 39: 272-284. 
Schwanghart W, Groom G, Kuhn NJ, Heckrath G. 2013. Flow network derivation from a high resolution DEM in a low relief, agrarian landscape. Earth Surface Processes and Landforms 38: 1576-1586, DOI: 10.1002/esp.3452.

Siart C, Forbriger M, Nowaczinski E, Hecht S, Höfle B. 2013. Fusion of multi-resolution surface (terrestrial laser scanning) and subsurface geodata (ERT, SRT) for karst landform investigation and geomorphometric quantification. Earth Surface Processes Landforms 38: 1135-1147, DOI: 10.1002/esp.3394.

Smith MJ, Rose J, Gousie MB. 2009. The Cookie Cutter: A method for obtaining a quantitative 3D description of glacial bedforms. Geomorphology 108: 209-218.

Sofia G, Tarolli P, Cazorzi F, Dalla Fontana G. 2011. An objective approach for feature extraction: distribution analysis and statistical descriptors for scale choice and channel network identification. Hydrology and Earth System Sciences 15: 1387-1402, DOI:10.5194/hess-15-1387-2011.

Sofia G, Pirotti F, Tarolli P. 2013. Variations in multiscale curvature distribution and signatures of LiDAR DTMs errors. Earth Surface Processes and Landforms 38: 11161134, doi:10.1002/esp.3363.

Staley DM, Wasklewicz TA, Blaszczynski JS. 2006. Surficial patterns of debris flow deposition on alluvial fans in Death Valley, CA using airborne laser swath mapping data. Geomorphology 74: 152-163.

Székely B, Koma Z, Karátson D, Dorninger P, Wörner G, Brandmeier M, Nothegger C. 2014. Automated recognition of quasi-planar ignimbrite sheets as paleosurfaces via robust segmentation of digital elevation model: an example from the Central Andes. Earth Surface Processes and Landforms. DOI: xxxxx. 
Tarolli P, Sofia G, Dalla Fontana G. 2012. Geomorphic features extraction from highresolution topography: landslide crowns and bank erosion. Natural Hazards 61: 65-83, DOI:10.1007/s11069-010-9695-2.

Tarolli P. 2014. High-resolution topography for understanding Earth surface processes: opportunities and challenges. Geomorphology 216: 295-312, DOI:10.1016/j.geomorph.2014.03.008.

Tseng CM, Lin CW, Stark CP, Liu JK, Fei LY, Hsieh YC. 2013. Application of a multitemporal, LiDAR-derived, digital terrain model in a landslide-volume estimation. Earth Surface Processes and Landforms 38: 1587-1601, DOI:10.1002/esp.3454.

Zhao C, Zhang Q, Yin Y, Lu Z, Yang C, Zhu W, Li B. 2013. Pre-, co-, and postrockslide analysis with ALOS/PALSAR imagery: a case study of the Jiweishan rockslide, China. Natural Hazards and Earth System Sciences 13: 2851-2861, DOI:10.5194/nhess-13-2851-2013. 